\title{
Free Radical Scavenging Capacity and Total Phenolic Contents in Peel and Fleshy Crude Extracts of Selected Vegetables
}

\author{
Chanate Wanna*
}

\section{Chanate Wanna*}

Division of Biology, Faculty of Science and Technology, Suan Sunandha Rajabhat University, Bangkok 10300, THAILAND.

\section{Correspondence}

\section{Chanate Wanna}

Division of Biology, Faculty of Science and Technology, Suan Sunandha Rajabhat University, Bangkok 10300, THAILAND.

E-mail: chanate.wa@ssru.ac.th

History

- Submission Date: 30-07-2019;

- Review completed: 21-08-2019;

- Accepted Date: 21-08-2019

DOI : 10.5530/pj.2019.11.209

Article Available online

http://www.phcogj.com/v11/i6

\section{Copyright}

(C) 2019 Phcogj.Com. This is an openaccess article distributed under the terms of the Creative Commons Attribution 4.0 International license.

\begin{abstract}
Context: Vegetables are sources of natural antioxidants which have beneficial health-promoting properties. Aims: This research was conducted to evaluate the antioxidant potentials and total phenolic contents in vegetable extracts. Settings and Design: The experiment was divided two groups using six vegetable peels and fleshes, including potato (Solanum tuberosum L.), carrot (Daucus carota L.), bitter gourd (Monordica Charantia L.), pumpkin (Cucurbita moschana Duchesn), Chinese radish (Raphanus sativus L.), and cucumber (Cucumis sativus L.). Materials and Methods: The samples were extracted with $95 \%$ ethanol for $24 \mathrm{hrs}$ and then analyzed the antioxidant activities by DPPH and FRAP assay and total phenolic contents was determined by Folin-Ciocalteu assay. Statistical analysis used: All the analysis was done in triplicate, and values are represented as means \pm standard deviations. The data were subjected to one-way analysis of variance (ANOVA) and significance differences between mean values were determined by Tukey's multiple comparison tests $(p<0.05)$. Pearson correlation coefficient was determined between the antioxidant activities and total phenolic contents using SPSS version 21. Results: The results revealed that antioxidant activities were different statistically significant in each group $(p<0.05)$. Carrot peel was the most potent in DPPH radical scavenging activity $(61.80 \pm 6.14 \%)$ and reducing power $(0.75 \pm$ $0.25 \mathrm{mM} \mathrm{Fe}{ }^{2+} / \mathrm{g}$ extract) and potato flesh could inhibit DPPH radical (35.60 $\left.\pm 0.63 \%\right)$ and had the highest FRAP value $\left(0.61 \pm 0.78 \mathrm{mM} \mathrm{Fe}^{2+} / \mathrm{g}\right.$ extract). Pumpkin peel and Chinese radish flesh had the most total phenolic contents as $110.45 \pm 22.49$ and $142.15 \pm 3.53 \mathrm{mg}$ GAE/g extract, respectively. Although no correlations was between antioxidant activities and total phenolic contents in extracts but were significant correlations between DPPH and FRAP assay in vegetable peels and fleshes as 0.931 and 0.819 , respectively. Conclusion: This study substantiates the potential of vegetable peels to be used as functional foods and natural free radical scavengers.
\end{abstract}

Key words: Antioxidants, Free radicals, Total phenolic contents, Vegetable fleshes, Vegetable peels.

\section{INTRODUCTION}

The higher burden of free radicals causes an imbalance in homeostasis phenomena between oxidants and antioxidants in the body. ${ }^{1}$ This imbalance leads to oxidative stress that free radicals react with the importance cellular components such as protein, DNA and cell membrane to damage $^{2}$ and destroy the balance of the body system as well as lead to the deterioration or aging of cells and various diseases such as cancer, age-related neurodegeneration, high blood pressure, diabetes and cardiovascular disease. ${ }^{3-5}$ Antioxidants have attracted a great deal of attention as they are compounds that inhibit or delay the oxidation of other molecules by inhibiting the initiation or propagation of oxidizing chain reactions. There are two basic categories of antioxidants, namely, synthetic and natural. In general, synthetic antioxidants are compounds with phenolic structures of various degrees of alkyl substitution, whereas natural antioxidants can be phenolic compounds (tocopherols, flavonoids and phenolic acid), nitrogen compounds (alkaloids, chlorophyll derivatives, amino acids, and amine) or carotenoids. ${ }^{6,7}$ Among the natural antioxidants are non-toxic and biodegradable products and received much attention due to the best alternative to currently available synthetic antioxidants.

Vegetables have received increasing attention because they are edible plants which are known as a good source of dietary antioxidants or therapeutic agents for preventing oxidative stress-related diseases and in aging process due to the presence of various phytochemicals such as a-tocopherol, ascorbic acid, $\beta$-carotene and phenolic compounds. ${ }^{8-10}$ Epidemiological studies have found that the intake of vegetables has a strong inverse correlation with the risk of developing many chronic diseases. ${ }^{11-15}$ Current antioxidant researches are primarily focused on phenolic compounds, the principal components in vegetables responsible for healthpromoting substances and their antioxidant activity. ${ }^{8}$ In most cases, the waste by-products such as peels and seeds can present similar or higher contents of antioxidant and antimicrobial compounds. ${ }^{16}$ The higher amount of phenolic compounds and various vitamins has been reported in the peel than in pulp. ${ }^{17}$ Potato peel provides an excellent source for the recovery of phenolic compounds so it may offer an effective source of an antioxidant. ${ }^{18}$ Cucumber

Cite this article: Wanna C. Free Radical Scavenging Capacity and Total Phenolic Contents in Peel and Fleshy Crude Extracts of Selected Vegetables. Pharmacog J. 2019;11(6):1351-8. 
peel is considered a cheap source of flavonoids and can be used as a potential source of antioxidant for industrial applications. ${ }^{19}$ It has been shown that only fleshy part of the pumpkin is used in the food processing industry and $18-21 \%$ of the fruit is generated as pumpkin waste. ${ }^{20}$ Carrot processing peel is usually discarded or used as animal feed which is high in phenolics and antioxidant properties which could be considered for value-added utilization. ${ }^{21}$ Vegetable peels may be a great source of bioactive compounds especially antioxidants to utilize in the food industry. Furthermore, bitter gourd is an important vegetable grown in tropical and sub-tropical regions for biologically active compounds and its medicinal properties. ${ }^{22}$ Numerous studies confirm that the consumption of vegetables such as carrots, radishes, beets, pumpkin, broccoli, spinach, potato, bitter gourd and mushrooms where they contain high fiber and antioxidants to help the digestive system and excretory system regular, reduce the risk of colon cancer, lower cholesterol and reduce blood sugar levels as well as other diseases associated with free radicals. ${ }^{8,15,17,23-28}$

All of these aspects explain the increasing interest in vegetables that have been manifested in the past few years. Though many other vegetables have been investigated in the antioxidants generally there is still a need to find more information concerning the antioxidant potential of them as they are safe and also bioactive. Besides, it should be noted that the result may vary according to the geographical location, soil in which the plant is grown, season, varieties and method of extraction. Thus, the current study was undertaken to elucidate the antioxidant activity by DPPH and FRAP assay and determine total phenolic compounds by Folin-Ciocalteu assay from these selected local vegetable peels and fleshes in Thailand. The correlation between the antioxidant capacity and total phenolic contents was also determined to serve for human consumption which is safe and health-promoting, using as a nutraceutical and as a food preservative and the basic information to advanced research in further.

\section{MATERIALS AND METHODS}

\section{Chemicals and reagents}

All chemicals and reagents used in this study, such as 2,2-diphenyl1-picrylhydrazyl (DPPH), 6-hydroxy-2,5,7,8-tetramethyl chroman2-carboxylic acid (Trolox) 2,4,6-tris (2-pyridyl)-s-triazine (TPTZ), gallic acid monohydrate and Folin-Ciocalteu's phenol reagent were purchased from Sigma Chemical Company (St. Louis, MO, USA) and LOBA Chemie PVT. LTD., India. Other chemicals used (hydrochloric acid, acetic acid, sodium acetate, iron (III) chloride hexahydrate, ferrous (II) sulfate, sodium carbonate anhydrous and ethanol) were of analytical grade.

\section{Vegetable samples}

Six samples of fresh vegetable peels and fleshes were collected from the local market to conduct this study. The vegetables used for analysis were potato, carrot, bitter gourd, pumpkin, Chinese radish and cucumber (Table 1).

\section{Preparation of extracts}

To clean out and both peels and fleshes were cut into small pieces. Then they were dried in a hot air oven at $50^{\circ} \mathrm{C}$ until dry and their weights were recorded. The six vegetable samples of both peel and flesh groups were weighed. By weighing the peel $6 \mathrm{~g}$ of added ethanol $10 \mathrm{ml}$ and weigh the flesh $15 \mathrm{~g}$ of added ethanol $25 \mathrm{ml}(3: 5 \mathrm{w} / \mathrm{v})$ macerated for 24 hours between both groups after that filters out the residue by filter paper. Bring the liquid to filter out the ethanol using a rotary evaporator at 80 ${ }^{\circ} \mathrm{C}$ until a viscous substance and dried by freeze dryer, dried extracts weighed and recorded. Store the extracts within the sealed container in the refrigerator to be tested for antioxidant activity and total phenolic compounds in the extracts.

\section{2, 2-Diphenyl-1-picrylhydrazyl (DPPH) radical scavenging activity assay}

This assay was used to evaluate the antioxidant activity of extracts from purple to yellow through 2, 2-diphenyl-1-picrylhydrazyl (DPPH) scavenging system and determined using the method outlined by Seephonkai et al. (2011). ${ }^{29}$ The stock of $0.3 \mathrm{mM}$ DPPH solution was prepared by dissolving $5.9 \mathrm{mg}$ DPPH powder in $50 \mathrm{ml}$ of ethanol, sealed in aluminum foil and kept in a fridge. A100 $\mu$ l aliquot of the extract was mixed with $900 \mu \mathrm{l}$ of freshly prepared $0.3 \mathrm{mM} \mathrm{DPPH}$ solution. The mixture was shaken vigorously and kept in dark for 30 min at room temperature. The reaction mixture was measured against a blank (ethanol) at $515 \mathrm{~nm}$ with a UV-VIS spectrophotometer (Thermo GENESYS 20). Each free radical scavenging activity assay was carried out in triplicate from the same extract to determine their reproducibility and the results were expressed as the percentage of free radical DPPH scavenging activity of the extract using Trolox as a positive control in two groups was calculated as:

DPPH scavenging activity $(\%)=\left[\left(\mathrm{A}_{\text {control }}-\mathrm{A}_{\text {sample }}\right) / \mathrm{A}_{\text {control }}\right] \times 100$

Where, $A_{\text {control }}$ is the absorbance of control solution containing only $\mathrm{DPPH}$

$\mathrm{A}_{\text {sample }}$ is the absorbance of extract in DPPH solution

\section{Ferric reducing antioxidant power (FRAP) assay}

The ferric reducing ability of different extracts was estimated by the method of Benzie and Strain (1996). ${ }^{30}$ This assay uses antioxidants as reductants in the redox-linked colorimetric method. The FRAP reagent was prepared by mixing $0.2 \mathrm{M}$ acetate buffer, $\mathrm{pH} 3.6(0.2 \mathrm{M}$ acetic acid $46.3 \mathrm{ml}$ and $0.2 \mathrm{M}$ sodium acetate $3.7 \mathrm{ml}$ ), $1 \mathrm{mM}$ TPTZ (2,4,6-tris (2pyridyl)-s-triazine) in $40 \mathrm{mM} \mathrm{HCl}$ and $20 \mathrm{mM} \mathrm{FeCl}_{3} \cdot 6 \mathrm{H}_{2} \mathrm{O}$ in the ratio of 10:1:1 to mix the working reagent and then incubate $37^{\circ} \mathrm{C}$ for $20 \mathrm{~min}$. Triplicates of $100 \mu \mathrm{l}$ of extract were added with $1.5 \mathrm{ml}$ of FRAP reagent and kept in dark for $30 \mathrm{~min}$ at room temperature. The reduction of ferric $\left(\mathrm{Fe}^{3+}\right)$ (colorless) to ferrous $\left(\mathrm{Fe}^{2+}\right)$ (blue) can be monitored by measuring absorbance at $595 \mathrm{~nm}$ wavelength using a UV-VIS spectrophotometer after $30 \mathrm{~min}$. Calibration curve of ferrous (II) sulfate $\left(\mathrm{FeSO}_{4}\right)$ at 0.2 , $0.4,0.6,0.8,1.0$ and $1.2 \mathrm{mM} \mathrm{Fe}^{2+}$ equivalents was set up to estimate the activity capacity of samples. Result was expressed as $\mathrm{mM}$ of $\mathrm{Fe}^{2+}$ equivalents per gram of extract ( $\mathrm{mM} \mathrm{Fe}^{2+} / \mathrm{g}$ extract).

\section{Determination of total phenolic contents (TPC)}

A modified method by Tibuhwa (2014) $)^{31}$ was used to determine the total phenolic content of the extracts. Briefly, Each $100 \mu \mathrm{l}$ of extracts were mixed thoroughly with $900 \mu \mathrm{l}$ of $10 \%$ Folin-Ciocalteau's reagent and

Table 1: Taxonomic of vegetables selected for study.

\begin{tabular}{cccc}
\hline Sample No. & Vegetables & Scientific name & Family \\
\hline 1 & Potato & Solanum tuberosum L. & Solanaceae \\
2 & Carrot & Daucus carota L. & Apiaceae \\
3 & Bitter gourd & Monordica Charantia L. & Cucurbitaceae \\
4 & Pumpkin & Cucurbita moschana Duchesna & Cucurbitaceae \\
5 & Chinese radish & Raphanus sativus L. & Brassicaceae \\
6 & Cucumber & Cucumis sativus L. & Cucurbitaceae \\
\hline
\end{tabular}


kept for $8 \mathrm{~min}$ at room temperature. Then $400 \mu \mathrm{l}$ of $7.5 \%$ (w/v) sodium carbonate was added to the mixture and was allowed to stand for 60 min. The absorbance of extract and prepared blank were measured at $765 \mathrm{~nm}$ for blue colored complex using UV-VIS spectrophotometer. The test was analyzed in triplicate and constructed the calibration curve with different concentrations of gallic acid at 1, 5, 10, 20, 40, 60 and 80 $\mu \mathrm{g} / \mathrm{ml}$. The results were expressed as milligram of gallic acid equivalents (GAE) per gram of extract (mg GAE/g extract).

\section{Statistical analysis}

All experiments were done in triplicate $(n=3)$. The results were expressed as means \pm standard deviations and analyzed by using Statistical Package for Social Sciences (SPSS version 21). The data were statistically analyzed using one-way analysis of variance (ANOVA) followed by Tukey's multiple comparison tests at $95 \%$ least significance difference $(p<0.05)$. The Pearson correlation coefficient was used to determine the relationship between the antioxidant activity and total phenolic contents in sample extracts. Differences between means at $p<$ 0.05 level were considered to be significant.

\section{RESULTS}

Vegetable peels and fleshes were macerated using 95\% ethanol and concentrated using a rotary evaporator to obtain a viscous ethanolic extract. The ethanolic extracts were the viscous concentrated brown extracts and total yield of extracts were ranging from 1.90 to $6.78 \%$. The highest yield was contributed to pumpkin flesh and had the lowest yield in bitter gourd peel (Table 2).

\section{DPPH radical scavenging activity assay}

The extracts from six vegetable peels and fleshes were continued to antioxidant activity test using DPPH assay which measures the ability to inhibit DPPH free radical happened. The results obtained from this study are the percentage of inhibition. Trolox was used as a standard in this test. Based on Table 3 and Figure 1, it found that vegetable peels were a statistically significant difference in anti-oxidation caused by DPPH free radicals (F-test $=58.98, p<0.05)$. The carrot peel could inhibit free radicals the highest as $61.80 \pm 6.14 \%$, followed by potato peel $(59.02 \pm 6.64 \%)$, Chinese radish $(41.30 \pm 2.84 \%)$, pumpkin

Table 2: Total yield of crude extracts from vegetables.

\begin{tabular}{ccc}
\hline \multirow{2}{*}{ Vegetable samples } & \multicolumn{3}{c}{ Extract yield (\%) } \\
\cline { 2 - 3 } & Peel & Flesh \\
\hline potato & 2.43 & 4.35 \\
carrot & 3.86 & 6.63 \\
bitter gourd & 1.90 & 2.75 \\
pumpkin & 4.29 & 6.78 \\
Chinese radish & 2.23 & 3.65 \\
cucumber & 2.56 & 3.13 \\
\hline
\end{tabular}

Table 3: The ability of antioxidants and total phenolic contents in the six vegetable peel extracts.

\begin{tabular}{cccc}
\hline Vegetable samples & $\begin{array}{c}\text { DPPH assay } \\
\text { (\% inhibition) }\end{array}$ & $\begin{array}{c}\text { FRAP assay } \\
\text { (mM Fe } \text { (m }^{2+} \text { extract) }\end{array}$ & $\begin{array}{c}\text { Folin-Ciocalteau } \\
\text { (mg GAE/g extract) }\end{array}$ \\
\hline potato & $59.02 \pm 6.64^{\mathrm{c}}$ & $0.59 \pm 0.06^{\mathrm{b}}$ & $75.48 \pm 11.05^{\mathrm{a}}$ \\
carrot & $61.80 \pm 6.14^{\mathrm{c}}$ & $0.75 \pm 0.03^{\mathrm{c}}$ & $87.90 \pm 3.45^{\mathrm{a}}$ \\
bitter gourd & $19.37 \pm 0.97^{\mathrm{a}}$ & $0.20 \pm 0.01^{\mathrm{a}}$ & $91.17 \pm 21.09^{\mathrm{a}}$ \\
pumpkin & $37.04 \pm 1.52^{\mathrm{b}}$ & $0.56 \pm 0.07^{\mathrm{b}}$ & $110.45 \pm 22.49^{\mathrm{a}}$ \\
Chinese radish & $41.30 \pm 2.84^{\mathrm{b}}$ & $0.53 \pm 0.01^{\mathrm{b}}$ & $88.22 \pm 6.87^{\mathrm{a}}$ \\
cucumber & $24.08 \pm 0.59^{\mathrm{a}}$ & $0.27 \pm 0.02^{\mathrm{a}}$ & $51.95 \pm 10.61^{\mathrm{a}}$ \\
trolox & $58.77 \pm 0.23^{\mathrm{c}}$ & - & - \\
\hline
\end{tabular}

Values are expressed as mean $\pm \mathrm{SD}(\mathrm{n}=3)$ of triplicate measurements.

Different letters in the column indicate significant differences at $p<0.05$.

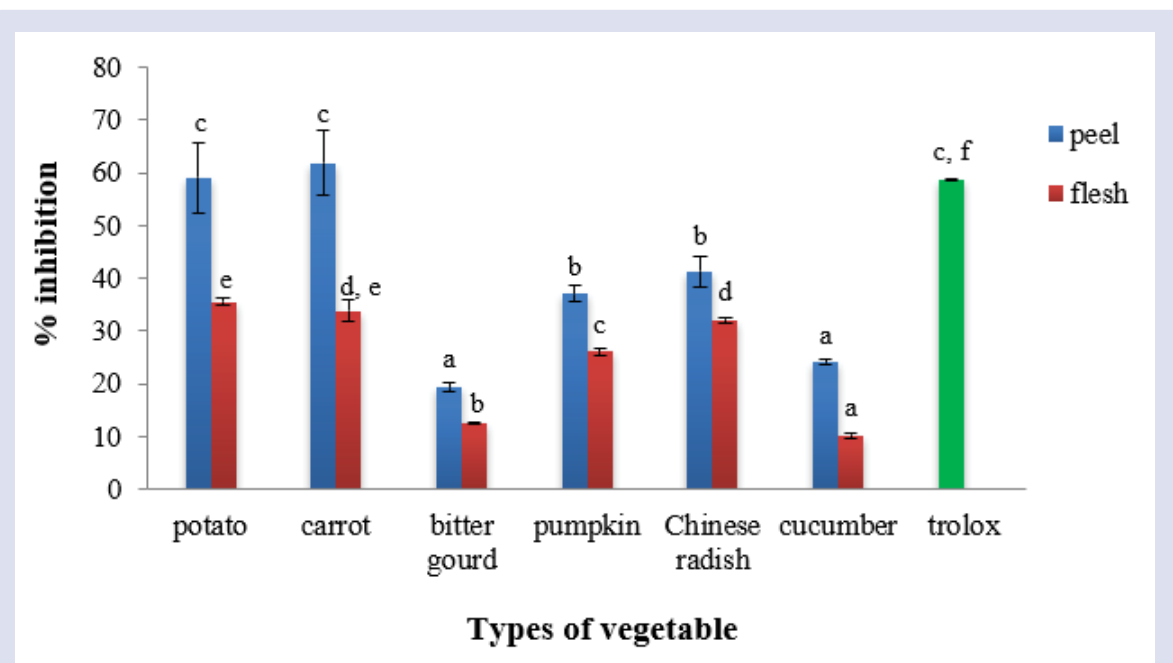

Figure 1: The ability of antioxidants of extracts from the peel and flesh in six vegetables by DPPH assay compared to the standard solution (trolox) $0.5 \mathrm{mM}$. 
(37.04 $\pm 1.52 \%)$, cucumber $(24.08 \pm 0.59 \%)$ and bitter gourd $(19.37 \pm$ $0.97 \%)$, respectively. The DPPH inhibition of carrot and potato peels was significantly different from other vegetable peels and higher than the positive control (trolox). This result indicated that the antioxidant activity of carrot and potato peels was better than trolox. The antioxidant activity of flesh extracts was statistically significant differences (F-test $=$ 499.76, $p<0.05)$. By order of their ability to inhibit the highest to the lowest as potato, carrot, Chinese radish, pumpkin, bitter gourd, and cucumber was equal to $35.60 \pm 0.63 \%, 33.86 \pm 1.92 \%, 32.07 \pm 0.58 \%$, $26.10 \pm 0.71 \%, 12.63 \pm 0.16 \%$ and $10.17 \pm 0.43 \%$, respectively (Table 4 and Figure 1). Percentage of inhibition in the potato flesh was not statistically different with carrot and Chinese radish flesh but unlike other types of flesh. It found that the DPPH inhibitory effect of peel was higher than flesh in all vegetables.

\section{Ferric reducing antioxidant power (FRAP) assay}

FRAP assay measures the electron-donating capacity of an antioxidant present in the test compound reacting with a ferric tripyridyltriazine $\left(\mathrm{Fe}^{3+}-\mathrm{TPTZ}\right)$ complex and forms a colored ferrous tripyridyltriazine $\left(\mathrm{Fe}^{2+}-\mathrm{TPTZ}\right)$. Ferrous (II) sulfate was used as the standard in this assay and produced the calibration curve against the standard to obtain the regression equation, $\mathrm{y}=0.7114 \mathrm{x}+0.2407$ with $\mathrm{R}^{2}$ of 0.9995 (Figure 3 ). The reaction can be monitored ferrous ions $\left(\mathrm{Fe}^{2+}\right)$ performed as the reducing power or FRAP value. When tested for antioxidant activity of the extracts from the peel and flesh of six vegetables by FRAP assay, that peel had anti-oxidation caused by $\mathrm{Fe}^{3+}$ free radicals statistically significant difference (F-test $=79.00, p<0.05)$. By order of their ability to inhibit the highest to the lowest as carrot, potato, pumpkin, Chinese radish, cucumber and bitter gourd was equal to $0.75 \pm 0.03,0.59 \pm$ $0.06,0.56 \pm 0.07,0.53 \pm 0.01,0.27 \pm 0.02$ and $0.20 \pm 0.01 \mathrm{mM} \mathrm{Fe} \mathrm{F}^{2+} / \mathrm{g}$ extract, respectively (Table 3 and Figure 2). Carrot peel had the amount of $\mathrm{Fe}^{2+}$ different from other vegetables but the potato, pumpkin and Chinese radish peel were not statistically different and the antioxidant of extracts from flesh found a statistically significant difference $($ F-test $=$ $64.45, p<0.05)$. The potato flesh had a highest value of $0.61 \pm 0.08 \mathrm{mM}$ $\mathrm{Fe}^{2+} / \mathrm{g}$ extract, followed by the pumpkin, Chinese radish, carrot, bitter gourd and cucumber as $0.56 \pm 0.02,0.50 \pm 0.02,0.38 \pm 0.01,0.29 \pm 0.02$ and $0.18 \pm 0.03 \mathrm{mM} \mathrm{Fe}^{2+} / \mathrm{g}$ extract, respectively (Table 4 and Figure 2). Pumpkin flesh had the amount of $\mathrm{Fe}^{2+}$ no differ statistically with potato and Chinese radish. It also found that the ability to reducing of their peel and flesh were mostly similar but carrot peel was greatly higher than carrot flesh.

\section{Total phenolic contents}

In this study was also measured total phenolic content. Total phenolic contents in the peel and flesh extracts of six vegetables was determined using Folin-Ciocalteu assay. Gallic acid was used as a standard in this test and produces a linear regression equation, $\mathrm{y}=0.0090 \mathrm{x}+1.0116$ with $\mathrm{R}^{2}$ of 0.9997 (Figure 5). The total phenolic contents of ethanol extracts can be calculated using the regression equation obtained. From the results, it can be seen that the total phenolic contents of vegetable peel extracts were not a statistically significant differences $($ F-test $=$ $1.42, p>0.05)$. In order to the highest to lowest are as the following of pumpkin, bitter gourd, Chinese radish, carrot, potato and cucumber equal to $110.45 \pm 22.49,91.17 \pm 21.09,88.22 \pm 6.87,87.90 \pm 3.45,75.48$ \pm 11.05 and $51.95 \pm 10.61 \mathrm{mg} \mathrm{GAE} / \mathrm{g}$ extract, respectively (Table 3 and Figure 4). Total phenolic contents of vegetable fleshes with a difference was statistically significant $(\mathrm{F}$-test $=28.05, p<0.05)$. The Chinese radish flesh had the highest of total phenolic contents as $142.15 \pm 3.53 \mathrm{mg}$ GAE/g extract, followed by the carrots, pumpkin, and bitter gourd, potato and cucumber were $132.02 \pm 10.91,116.66 \pm 7.78,108.49 \pm$ $13.91,34.30 \pm 16.67$ and $33.00 \pm 6.53 \mathrm{mg} \mathrm{GAE} / \mathrm{g}$ extract, respectively

Table 4: The ability of antioxidants and total phenolic contents in the six vegetable fleshy extracts.

\begin{tabular}{|c|c|c|c|}
\hline Vegetable samples & $\begin{array}{c}\text { DPPH assay } \\
\text { (\% inhibition) }\end{array}$ & $\begin{array}{c}\text { FRAP assay } \\
\text { (mM Fe}{ }^{2+} / \mathrm{g} \text { extract) }\end{array}$ & $\begin{array}{c}\text { Folin-Ciocalteau } \\
\text { (mg GAE/g extract) }\end{array}$ \\
\hline potato & $35.60 \pm 0.63^{\mathrm{e}}$ & $0.61 \pm 0.08^{\mathrm{e}}$ & $34.30 \pm 16.67^{\mathrm{a}}$ \\
\hline bitter gourd & $12.63 \pm 0.16^{\mathrm{b}}$ & $0.29 \pm 0.02^{b}$ & $108.49 \pm 13.91^{b}$ \\
\hline pumpkin & $26.10 \pm 0.71^{\mathrm{c}}$ & $0.56 \pm 0.02^{\mathrm{d}, \mathrm{e}}$ & $116.66 \pm 7.78^{b}$ \\
\hline trolox & $58.77 \pm 0.23^{\mathrm{f}}$ & - & - \\
\hline
\end{tabular}

Values are expressed as mean $\pm \mathrm{SD}(\mathrm{n}=3)$ of triplicate measurements.

Different letters in the column indicate significant differences at $p<0.05$.

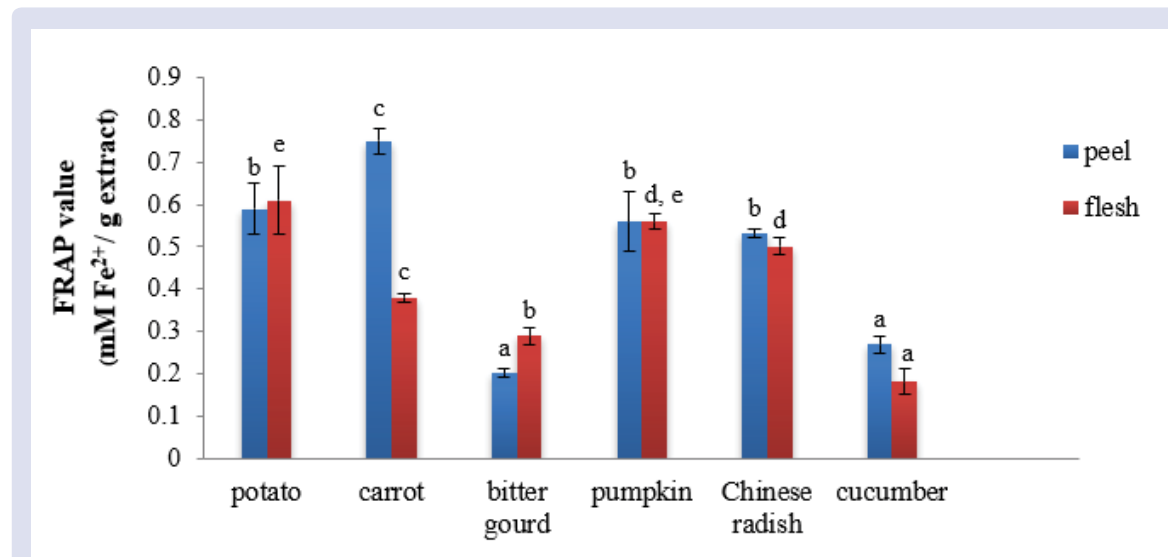

Types of vegetable

Figure 2: The reducing antioxidant power of extracts from the peel and flesh in six vegetables by FRAP assay compared with the standard calibration curve of ferrous (II) sulfate. 


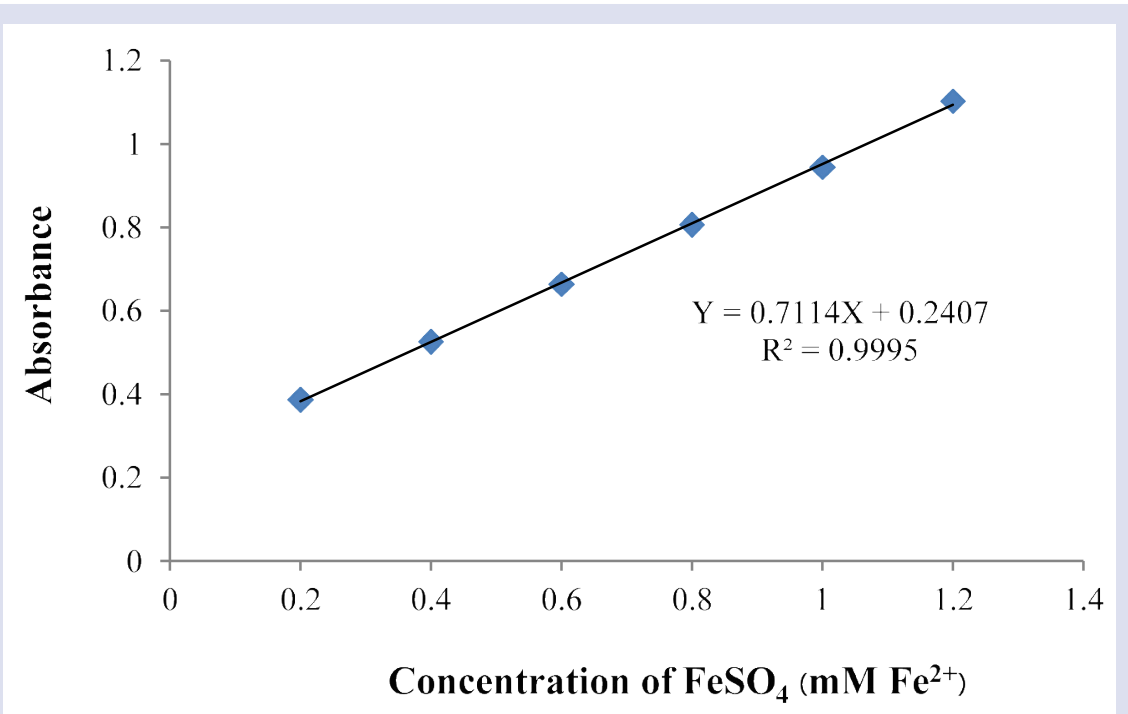

Figure 3: Standard calibration curve of ferrous (II) sulfate.

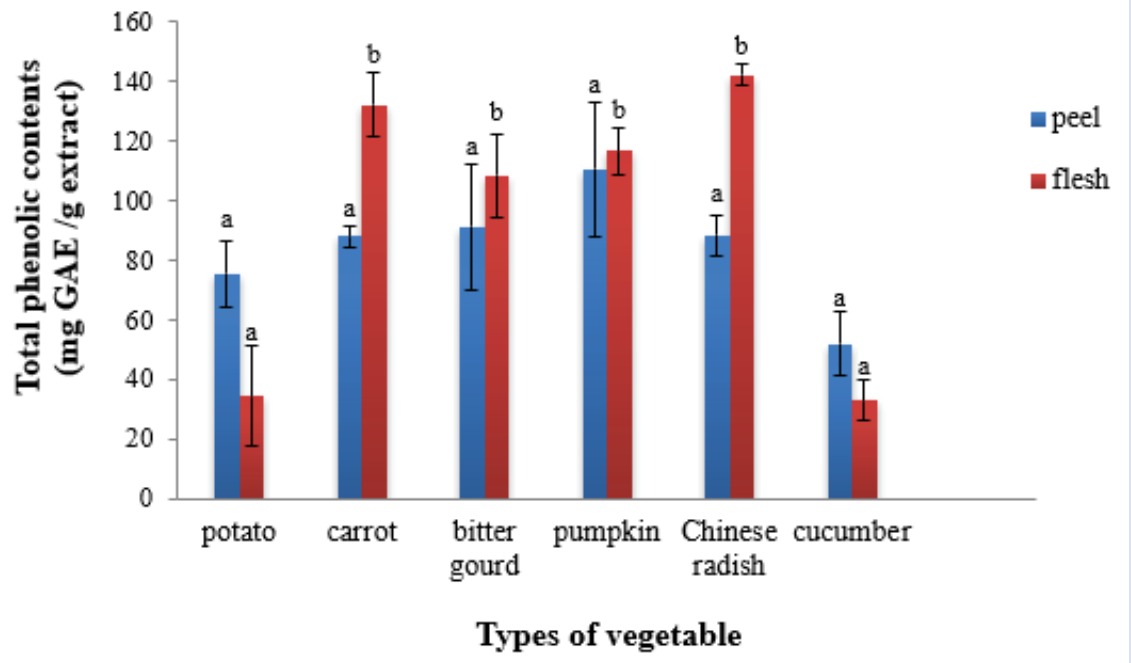

Figure 4: Total phenolic contents of six vegetable extracts from peel and flesh by Folin-Ciocalteu assay compared with the standard calibration curve of gallic acid.

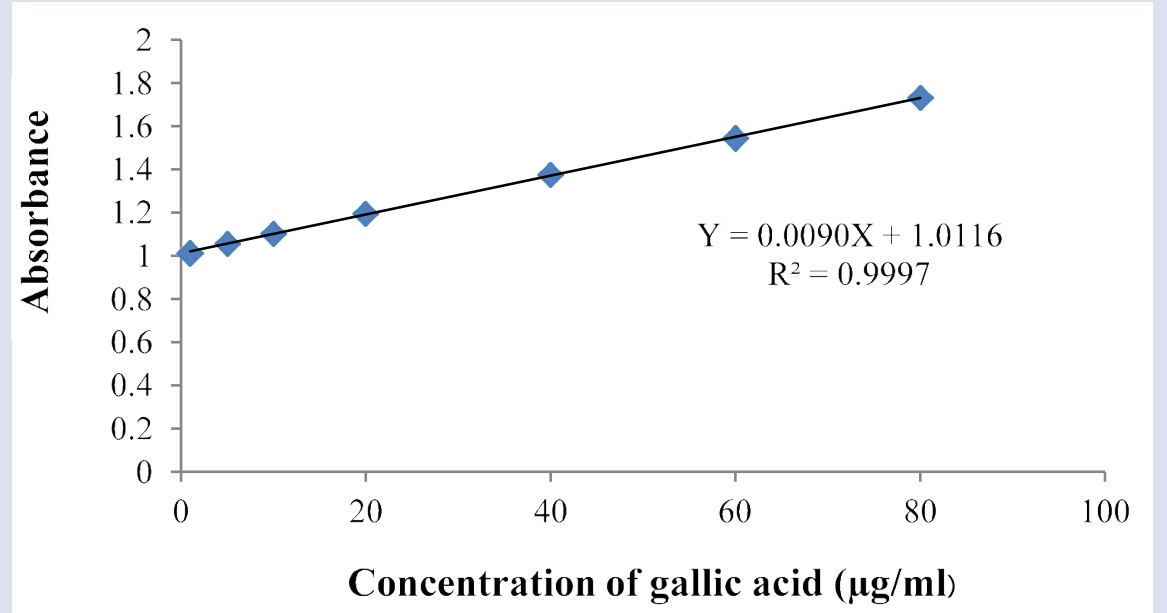

Figure 5: Standard calibration curve of gallic acid. 
Table 5: Correlation coefficients between antioxidant activities and total phenolic contents (TPC) of six vegetable peels and fleshes.

\begin{tabular}{ccccccc}
\hline \multirow{2}{*}{ Assay } & \multicolumn{3}{c}{ Vegetable peels } & \multicolumn{3}{c}{ Vegetable fleshes } \\
\cline { 2 - 7 } & DPPH & FRAP & TPC & DPPH & FRAP & TPC \\
\hline DPPH & - & 0.931 & 0.014 & - & 0.819 & 0.088 \\
FRAP & - & - & 0.126 & - & - & 0.030 \\
\hline
\end{tabular}

(Table 4 and Figure 4). The flesh was higher total phenolic contents than the peel and the Chinese radish and carrot flesh were higher total phenolic contents when compared with a standard solution of gallic acid.

\section{Correlation between antioxidant activity and total phenolic contents}

The Pearson correlation coefficients between the antioxidant abilities by DPPH and FRAP assay with total phenolic contents of six vegetable extracts were depicted in Table 5. As shown in this study, there was a low correlation $(r=0.014$ and 0.126$)$ in peels and the correlation in fleshes was also correlated similarly $(r=0.088$ and 0.030$)$, respectively. The peels correlated inversely with fleshes in DPPH and FRAP assay with total phenolic contents. In addition, a considerable correlation which was noted in DPPH and FRAP assay in peel and flesh of six vegetables showed a relatively high positive correlation $(\mathrm{r}=0.931$ and 0.819$)$ respectively. Overall, the result revealed the existence of a positive correlation between antioxidant assays and total phenolic contents.

\section{DISCUSSION}

The method used in antioxidant activity test is the DPPH radical uptake method because it is a simple, easy method, and uses a small amount of sample. ${ }^{29}$ In addition, this method does not require a substrate because free radicals are available directly to replace the substrate. Useful property in determining the non-enzymatic antioxidant values of vegetables is the capacity of the extracts to inhibit the free radical $\mathrm{DPPH}$. Antioxidants present in the extracts were expressed as the reduction of the purple-colored stable free radical 2, 2-diphenyl-1picrylhydrazyl (DPPH) to the yellow-colored diphenylpicryl hydrazine by donating an electron or hydrogen. This reduction of the free radical diminishes cellular damage by allowing the neutralization of reactive oxygen species present in the solution. ${ }^{32}$

The results of this study found that carrot peel extract was the highest of the ability to inhibit DPPH free radicals and the number of ferrous ions $\left(\mathrm{Fe}^{2+}\right)$ as compared to other vegetable peels. The reductive capacity of compound depends on the presence of reductones, which exhibit antioxidative potential by breaking the free radical chain and donating a hydrogen atom..$^{33}$ It was possible that extraction in ethanol was found to be more efficient than water in extracting the antioxidants present in vegetables; especially the carotenoids and the ethanolic extracts contained both polar and semi-polar compounds. The beta-carotene in carrots is capable to inhibit DPPH free radicals and also reducing ferric ions $\left(\mathrm{Fe}^{3+}\right)$ into ferrous ions $\left(\mathrm{Fe}^{2+}\right) .{ }^{34}$ But Eryngium foetidum (parsley) had the most antioxidant and the least antioxidant was carrot because bioactive compounds in parsley may be more antioxidant than beta-carotene in carrot. The antioxidants in carrot peel which contains variety of antioxidants such as vitamin $\mathrm{A}, \mathrm{B}, \mathrm{C}$, and betacarotene were the high quantity and found falcarinol substance in carrot which is useful in anticancer as well. ${ }^{35}$ There was also a study of the antioxidant activity of six vegetables by DPPH assay showed that Cratoxylum formosum (Tilapia) had the most antioxidant activity due to high chlorogenic acid when compared to total polyphenols. It was possible that carrot peel was capable of the most inhibition and may not be only phenolic compounds. ${ }^{36}$ From this result found that potato peel could inhibit free radicals inferior to carrot peel. The potato peel enriched several bioactive compounds such as vitamin A, B, C, beta-carotene, potassium, and minerals that help to eliminate free radicals. Ethanolic extracts from potato peel gave the highest phenolic content. As the evaluation of freeze-dried extracts by HPLC showed that gallic acid was the most phenolic compounds found in the extracts then caffeic acid, chlorogenic acid, protocatechuic acid, and vanillin respectively. ${ }^{37,38}$ Potato peel could inhibit free radicals due to various phenolic compounds and citric acid. ${ }^{39}$ Additionally, it was capable of reducing agents, iron-chelating capacity and inhibited the oxidation of linoleic acid. ${ }^{40}$

Pumpkin peel had the most total phenolic contents and also found carotenoids in the form of beta-carotene which has antioxidant properties include phenolic compounds. ${ }^{38,41}$ Pumpkin and carrot contained beta-carotene, a pigment of carotenoids which is a precursor in the synthesis of vitamin A, B1, B2, and C..$^{42}$ Vegetables that can inhibit free radicals comprised mainly phenolic compounds such as flavonoid, phenolic acid, and anthocyanin which were found in the vegetable peels. ${ }^{26}$ The analysis of total phenolic contents in six vegetable fleshes showed that Chinese radish was the most because it was composed of phenolic compounds include kaempferol, cytidine, triterpenes, gentisic acid, hydrocinnamic acid, vanillic acid, pelargonidin, luteolin, myricetin and quercetin. ${ }^{43}$

Each vegetable has total phenolic compounds and antioxidant activity differently due to the differences in the species cultivation, the extraction methods and environmental factors, such as climatic growth conditions, growth, ripening stage, temperature, duration of storage and thermal treatment may have influenced the antioxidant activity. ${ }^{44-46}$ The antioxidant activity of vegetable extracts also depends on the type and polarity of the extracting solvent, the isolation procedures and purity of active compounds, as well as the assay techniques and substrate used. ${ }^{47}$ The extraction solvent in this study was $70 \%$ ethanol while $100 \%$ acetone was used by Cao et al. (1996). ${ }^{25}$

In most vegetables, total phenolic compounds have been determined to be the main antioxidative compounds. Several studies have reported on the relationships between antioxidant activity and total phenolic contents. Some research found a correlation between the antioxidant activity and the phenolic contents, while others found no such relationship. The correlation between the antioxidant of plants 10 species by FRAP and TEAC was very high positive $(\mathrm{r}=0.917){ }^{48} \mathrm{It}$ is possible that both methods can be anti-oxidation though electron transferring mechanism. Other substances such as sugar, amine, ascorbic acid can be reduced Folin-Ciocalteu reagent change to blue resulting in too high phenolic compounds in those vegetables. ${ }^{49}$ Moreover, flavanones are capable of providing hydrogen atoms less than anthocyanins and flavonols which them are phenolic compounds. As a result, the vegetables which contain flavanones were determined to have antioxidant activity less than the other two groups lead to be not related to the real number of phenolic compounds..$^{50}$ In this study, the findings did not show any relationship (Table 4). For example, potato flesh had the lowest total phenolic contents whereas its antioxidant activity was higher than others. Pumpkin peel and bitter gourd peel and flesh had the high total phenolic contents although its antioxidant activity was quite the lowest (Tables 2 and 3). Carotenoids in pumpkin do not eliminate free radicals as well as phenolic compounds. The antioxidant may be due to the enzymes in vegetables such as peroxidase, catalase as could be seen from the potato extracts which eliminate free radicals so well in spite of the amount of phenolic compounds is low. ${ }^{51}$ The gallic acid was the predominant phenolic compound in the bitter gourd that was effective in reducing the stable radicle DPPH although the rate of reaction with DPPH is relatively low. ${ }^{32,52}$ 
According to the study in the antioxidant by DPPH and FRAP assay and total phenolic contents by Folin-Ciocalteu of six vegetable, ethanolic extract from peel and flesh found that carrot peel extract was the highest capacity of antioxidants as $61.80 \pm 6.14 \%$ and $0.75 \pm 0.03 \mathrm{mM}$ $\mathrm{Fe}^{2+} / \mathrm{g}$ extract respectively. Potato flesh extract was the best antioxidant of $35.60 \pm 0.63 \%$ and $0.61 \pm 0.08 \mathrm{mM} \mathrm{Fe}^{2+} / \mathrm{g}$ extract respectively. The highest and lowest total phenolic contents in peel were pumpkin and cucumber equal to $110.45 \pm 22.49$ and $51.95 \pm 10.61 \mathrm{mg} \mathrm{GAE} / \mathrm{g}$ extract respectively. Extract from Chinese radish flesh had the highest total phenolic contents as $142.15 \pm 3.53 \mathrm{mg} \mathrm{GAE} / \mathrm{g}$ extract and extract from cucumber was the lowest as $33.00 \pm 6.53 \mathrm{mg} \mathrm{GAE} / \mathrm{g}$ extract. Besides, the ability of antioxidants did not correlate with the total phenolic contents.

\section{CONCLUSION}

These results suggested that the antioxidant activities and the presence of phenolic compounds in six vegetable peels and fleshes can serve as a potential source of antioxidants to protect against free radical damage, which could be useful in the prevention of diseases. This may be useful information for identifying processing waste materials that are rich in these protective components for the development of food products with appropriate antioxidant properties. Further studies in peel and flesh are warranted to validate its functional and physiological benefits for utilizing antioxidants containing extracts as nutraceuticals and in food industries for human consumption which are safe and healthpromoting.

\section{ACKNOWLEDGEMENT}

The author gratefully acknowledges the Institute for Research and Development to support a grant and necessary support of this work by Faculty of Science and Technology, Suan Sunandha Rajabhat University, Bangkok, Thailand.

\section{CONFLICT OF INTEREST}

The author declared no conflict of interest.

\section{ABBREVIATION}

DPPH: 2, 2-Diphenyl-1-picrylhydrazyl; FRAP: Ferric reducing antioxidant power; GAE: Gallic acid equivalents; TPC: Total phenolic contents.

\section{REFERENCES}

1. Pavithra K, Vadivukkarasi S. Evaluation of free radical scavenging activity of various extracts of leaves from Kedrostis foetidissima (Jacq.) Cogn. Food Science and Human Wellness. 2015;4(1):42-6.

2. Mantena RKR, Wijburg OLC, Vindurampulle C, Bennett-Wood VR, Walduck A, Drummond GR, et al. Reactive oxygen species are the major antibacterial against Salmonella typhimurium purine auxotrophs in the phagosome of RAW2647.7 cells. Cell Microbiology. 2008;10:1058-73.

3. Hereberg S, Galan P, Preziosi P, Alfarez M, Vasquez C. The potential role of antioxidant vitamins in preventing cardiovascular diseases and cancers. Nutrition. 1998;14:513-20.

4. Wang SY, Jiao H. Scavenging capacity of berry crops on superoxide radicals, hydrogen peroxide, hydroxyl radicals, and singlet oxygen. Journal of Agricultural and Food Chemistry. 2000;48:5672-6.

5. Skerget M, Kotnik P, Hadolin M, Hras AR, Simonic M, Knez Z. Phenols, proanthocyanidins, flavones and flavonols in some plant materials and their antioxidant activities. Food Chemistry. 2005;89(2):191-8.

6. Hudson BJF. Ed. Food Antioxidants. Elsevier Applied Science: London; 1990.

7. Hall CA, Cuppett SL. Structure-activities of natural antioxidants. In Antioxidant Methodology In Vivo and In Vitro Concepts; Aruoma, OI, Cuppett, SL, Eds.; AOCS Press: Champaign, IL; 1997. p. 2-29.

8. Kaur C, Kapoor HC. Anti-oxidant activity and total phenolic content of some Asian vegetables. International Journal of Food Science and Technology. 2002;37:153-61.

9. Manach C, Scalbert A, Morand C, Remesy C, Jimenez L. Polyphenols: food sources and bioavailability. The American Journal of Clinical Nutrition. 2004;79(5):727-47.
10. Kalt W. Effects of production and processing factors on major fruit and vegetable antioxidants. Journal of Food Science 2005;70:11-9

11. Block G, Patterson B, Subar A. Fruit, vegetables, and cancer prevention: $A$ review of the epidemiological evidence. Nutrition and Cancer. 1992;18:1-29.

12. Lunet $N$, Lacerda-Vieira $A$, Barros $H$. Fruit and vegetables consumption and gastric cancer: A systematic review and meta-analysis of cohort studies. Nutrition and Cancer. 2005;53:1-10.

13. Michels KB, Giovannucci E, Chan AT, Singhania R, Fuchs CS, Willett WC. Fruit and vegetable consumption and colorectal adenomas in the nurses' health study. Cancer Research. 2006;66:3942-53.

14. He F, Nowson C, Lucas M, Macgregor G. Increased consumption of fruit and vegetables is related to a reduced risk of coronary heart disease: Meta-analysis of cohort studies. Journal of Human Hypertension. 2007;21:717-28.

15. Schaffer S, Schmidt-Schillig S, Muller WE, Eckert GP. Antioxidant properties of mediterranean food plant extract geographical differences. Journal of Physiology and Pharmacology. 2007;56(Suppl.1):115-24.

16. Ayala-Zavala JF, Wang SY, Wang CY, Gonzalez-Aguilar GA. Effect of temperature on antioxidant capacity and aroma compounds in strawberry fruit. LWT-Food Science and Technology. 2004;37:687-95.

17. Goulas $V$, Manganaris GA. Exploring the phytochemical content and the antioxidant potential of citrus fruits grown in Cyprus. Food Chemistry. 2012;131:39-47.

18. Friedmen M. Chemistry, biochemistry and dietary role of potato polyphenols. Journal of Agricultural and Food Chemistry. 1997;45:1523-40.

19. Agarwal M, Kumar A, Gupta R, Upadhyaya S. Extraction of polyphenol, flavanoid from Emblica officinalis, Citrus limon, Cucumis sativus and evaluation of their antioxidant activity. Oriental Journal of Chemistry. 2012;28:993-8.

20. Mala S, Kurian A. Nutritional composition and antioxidant activity of pumpkin waste. International Journal of Pharmaceutical, Chemical and Biological Sciences. 2016;6(3):336-44.

21. Hager TJ, Howard LR. Processing effects on carrot phytonutrients. Horticultural Science. 2006;41:74-9.

22. Begum S, Ahmed M, Siddiqui BS, Khan A, Saify ZS, Arif M. Triterpenes, a sterol, and a monocyclic alcohol from Momordica charantia. Phytochemistry. 1997;44(7):1313-20.

23. Ames BM, Shinena MK, HagenTM. Oxidants, antioxidants and the degenerative disease of aging. Proceedings of the National Academy of Sciences of the United States of America. 1993;90:7915-22.

24. Gillman MW, Cupples LA, Gagnon D, Posner BM, Ellison RC, Castelli WP, Wolf PA. Protective effect of fruits and vegetables on development of stroke in men. JAMA. 1995;273:113-7.

25. Cao G, Sofic E, Prior RL. Antioxidant capacity of tea and common vegetables. Journal Agricultural and Food Chemistry. 1996;44:3426-31.

26. Barros L, Ferreira MJ, Queiros B, Ferreira ICFR, Baptista P. Total phenols, ascorbic acid, $\beta$-carotene and lycopene in Portuguese wild edible mushrooms and their antioxidant activities. Food Chemistry. 2007;103(2):413-9.

27. Hina A, Narjis N. Free radical scavenging activity of pulps and peels of some selected vegetables commonly used in Pakistan. Pakistan Journal of Agricultural Research. 2017;30 (1):55-66.

28. Wanna C, Sudhadham M. The effect of coconut water and boiling on antioxidant activity and total phenolic contents in Schizophyllum commune Fr. Pharmacognosy Journal. 2018;10 (5) :925-31.

29. Seephonkai P, Samchai S, Thongsom A, Sunaart S, Kiemsanmuang B, Chakuton K. DPPH radical scavenging activity and total phenolics of Phellinus mushrooms extracts collected from Northeast of Thailand. Chinese Journal of Natural Medicines. 2011;9(6):441-5.

30. Benzie IFF, Strain JJ. The ferric reducing ability of plasma (FRAP) as a measure of antioxidant power: the FRAP assay. Analytical Biochemistry. 1996;239:70-6.

31. Tibuhwa DD. A comparative study of antioxidant activities between fresh and dry mushrooms in the genera Cantharellus and Afrocantharellus from Tanzania. Food and Nutrition Science. 2014;5:212-21.

32. Wu S, Ng L. Antioxidant and free radical scavenging activities of wild bitter melon (Momordica charantia Linn. var. abbreviata Ser.) in Taiwan. LWT-Food Science and Technology. 2008;41:323-0.

33. Alasalvar C, Karamac M, Amarowicz R, Shahidi F. Antioxidant and antiradical activities in extracts of hazelnut kernel (Corylus avellena L.) and hazelnut green leafy cover. Journal of Agricultural and Food Chemistry. 2006;54:482632.

34. Biswas AK, Sahoo J, Chatli MK. A simple UV-Vis spectrophotometric method for determination of beta-carotene content in raw carrot, sweet potato and supplemented chicken meat nugges. Food Science and Technology. 2011;44:1809-13.

35. Buachum P, Wongsiri R, Innoi O. North Eastern Science and Technology Conference, Ubon Ratchathani Rajabhat University; 2015. 
36. Wangrug B, Piyasuwan S. Free radical scavenger of Thai vegetables [special project]. Faculty of Pharmacy, Mahidol University; $2006.41 \mathrm{pp}$.

37. Lisinska G, Leszczynski W. Potato Science and Technology. Elsevier Science Publishing Co., Inc., New York; 1989.391 pp.

38. Siwaporn S, Natthinee J. Extraction of phenolic compounds from potato peel. Proceedings of $41^{\text {th }}$ Kasetsart University Annual Conference: Agro-Industry. 2003;12-9.

39. Adisak J, Parichat T, Jintana J. Evaluation of antioxidant capacity in some local fruits in Chiang Mai, Thailand. Acta Horticulturae. 2015;1088:527-9.

40. Rowena GO, Rumbaoa DF, Cornago IM, Geronimo. Phenolic content and antioxidant capacity of Philippine potato (Solanum tuberosum) tubers. Journal of Food Composition and Analysis. 2009;22:546-55.

41. Srisamatthakarn $P$, Chanrittisen T, Panomwan N, Ayuthaya R, Kanobdee J, Duangchan W. Evaluation of Pumpkin (Cucurbita spp.) Quality and development of suitable process for pumpkin flour production for using as raw material in supplementary food products. Agricultural Technology Research Institute. Rajamangala University of Technology Lanna; 2015.71 pp.

42. Vichamanee Y. Development of ready to drink carrot-honey mixed juice [dissertation]. Kasetsart University; 1998.149 pp.

43. Jakmatakul S. Evaluation of antityrosinase and antioxidant activities of Raphnus sativus. methanolic extract. Thai Journal of Pharmaceutical Sciences. 2009;33:22-30

44. Ou B, Huang D, Woodill MH, Flanagan JA, Deemer EK. Analysis of antioxidant activities of common vegetables employing oxygen radical absorbance capacity (ORAC) and ferric reducing antioxidant power (FRAP) assays: a comparative study. Journal of Agricultural Food Chemistry. 2002;50:3122-28.
45. SangkitikomolW. Comparison of total phenolic compounds and total antioxidant activities of vegetable and Thai herb extracts. Journal of Allied Health Sciences. 2003;3:91-9.

46. Helmja K, Vaher M, Gorbatsova J, Kaljurand M. Characterization of bioactive compounds contained in vegetables of the Solanaceae family by capillary electrophoresis. Proceeding of the Estonian Academy of Sciences. Chemistry. 2007;56:172-86.

47. Meyer AS, Heinonen M, Frankel EN. Antioxidant interactions of catechin, cyanidin, cafeic acid, quercetin, and ellagicacid on human LDL oxidation. Food Chemistry. 1998;61:71-5.

48. Nuntnapas T. Total antioxidant activity, total phenolic compounds and vitamin $C$ in vegetables and herbs. Advanced Science Journal. 2008;8 (1):41-8.

49. Huang D, Ou B, Prior RL. The chemistry behind antioxidant capacity assays Journal of Agricultural and Food Chemistry. 2005;53:1841-56.

50. Proteggente AR, Pannala AS, Paganga G, Buren LV, Wagner E, Wiseman S, Van de Put $\mathrm{E}$. The antioxidant activity of regularly consumed fruit and vegetables reflects their phenolic and vitamin C composition. Free Radicals Research. 2002;36(2):217-33

51. Prior RL, Wu X, Schaich K. Standardized methods for the determination of antioxidant capacity and phenolics in foods and dietary supplements. Journa of Agricultural and Food Chemistry. 2005;53 (10):4290-302.

52. Lim YY, Lim TT, Tee JJ. Antioxidant properties of several tropical fruits: a comparative study. Food Chemistry. 2007;103(3):1003-8.

\section{GRAPHICAL ABSTRACT}
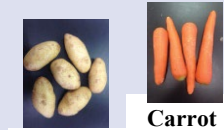

Potato Carrot

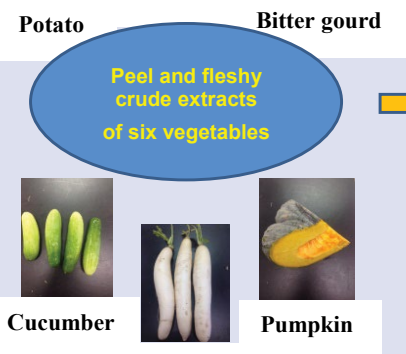

Chinese radish
Antioxidant capacity - DPPH assay - FRAP assay

Total phenolic contents - Folin-Ciocalteu assay

\section{SUMMARY}

- Carrot peel and potato flesh ethanolic was the highest antioxidants.

- The highest and lowest total phenolic contents in peel were pumpkin and cucumber, respectively.

- Chinese radish and cucumber fleshy extracts had the highest and lowest of total phenolic contents, respectively.

- The antioxidants ability in extract of six vegetables did not correlate with the total phenolic contents.

\section{ABOUT AUTHOR}

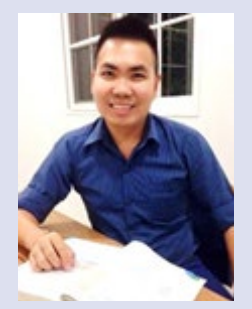

Chanate Wanna received his M.Sc. in Biochemistry, Faculty of Medicine, Siriraj Hospital, Mahidol University, Thailand. He is currently the lecturer at Division of Biology, Faculty of Science and Technology, Suan Sunandha Rajabhat University, Bangkok, Thailand. His research interests mainly focus on bioactivity of natural products, biochemical mechanisms in oxidative stress using in vitro culture models, zoology and biodiversity.

Cite this article: Wanna C. Free Radical Scavenging Capacity and Total Phenolic Contents in Peel and Fleshy Crude Extracts of Selected Vegetables. Pharmacog J. 2019;11(6):1351-8. 